Original Article

\title{
Preparation of Coronavirus Nosodes Sourced from a Clinical Sample of SARS-Cov-2 Positive Patient, Inactivated Strain, and Spike Glycoprotein
}

\author{
Sandeepan Mukherjee1, Gitanjali Talele ${ }^{2}$, Abhay Chowdhary ${ }^{3}$, Shashikant Vaidya ${ }^{4}$, Rajesh \\ Deshmukh5, Rakesh Rawal6, Rajesh Shah ${ }^{* 7}$
}

1 - HOD Virology department, Haffkine Institute for Training Research and Testing, 40/W, Acharya Dhonde Marg, Parel, Mumbai, 400012 - sandeepanm@gmail.com

2 - Research associate, Life Force Foundation Trust, 411 Krushal Commercial Complex, Chembur, Mumbai 400089 - geeta talele@rediffmail.com

3 - DM (Virology), FIMSA, FRSTMH, Prof \& Head of Microbiology, DY Patil University -

abhaychowdhary@yahoo.com

4 - Co-investigator, Assistant Director and HOD Microbiology department, Haffkine Institute for Training Research and Testing, 40/W, Acharya Dhonde Marg, Parel, Mumbai, 400012 - s.vaidya@haffkineinstitute.org

5 - Director and HOD Biopharmaceuticals department, Haffkine Institute for Training Research and Testing, 40/W, Acharya Dhonde Marg, Parel, Mumbai, 400012 - director@haffkineinstitute.org

6 - Professor, Dept of Life-Sciences, Gujarat University, Ahmedabad-38009 - rakeshmrawal@gmail.com

7 - Principal Investigator, Head of Research department, Life Force Foundation Trust, 411 Krushal Commercial Complex, Chembur, Mumbai 400089 - sanjivak@gmail.com

*sanjivak@gmail.com - https://orcid.org/0000-0002-1263-9077

\begin{abstract}
Introduction Nosodes, the homeopathic preparations sourced from biological materials including clinical samples, cultures of organisms, and diseased tissues have been in use against the sourcespecific infections as well as other diseases. The nosodes have demonstrated some efficacy in managing epidemics, such as influenza, dengue, and leptospirosis. This article presents the need and process of development of nosodes from the SARS-CoV-2 to explore its prophylactic and therapeutic potentials against certain related viral diseases. Materials and methods A clinical sample of SARSCov-2 positive patient, based on the cycle threshold (CT) value of the qRT-PCR, heat-inactivated SARS-CoV-2, and spike glycoprotein all were processed for making nosodes as per the method described in Homoeopathy Pharmacopoeia of India. Molecular tests, such as qRT- PCR and sterility tests were performed to establish the live organisms, RNA material, and the absence of contamination. Results Three variants of Coronavirus Nosode were developed using a clinical sample, heat-inactivated SARS-CoV-2, and spike glycoprotein. In potencies 3c and above, no detectable SARS-CoV-2 RNA material was found by PCR. The analytical results for nosodes were reported as compliant for sterility testing as per the IP. Conclusion Three variants of Coronavirus nosodes were prepared which need to be evaluated further through pre-clinical and clinical studies.

Keywords: Coronavirus, SARS-Cov-2, heat-inactivated, spike glycoprotein, nosode,
\end{abstract}

\section{Introduction}

With regards to the current COVID-19 pandemic caused by Severe Acute Respiratory Syndrome coronavirus 2 (SARS-CoV-2), there has not been an established cure and the prophylactic vaccines as 
on early August 2020. The highly infectious coronavirus disease started in China in November 2019, and, as on 24th August 2020, there have been 23.311.719 confirmed cases of COVID-19 in the world including 806.410 deaths in 216 countries as reported by the World Health Organization (WHO) (1).

Nosodes are homeopathic preparations sourced from biological materials, including clinical samples, organisms, cultures, and diseased tissues, that have been in use against source-specific infections or diseases and have demonstrated efficacy in the management of epidemics, such as Influenza (2), dengue (3), and leptospirosis (4), in observational human studies against HIV (5), Hepatitis C (6), and H3N2 (7), animal studies with H. pylori (8), Malaria (9), and E-coli (10), as well as in the cell-line experiments against Influenza (11) and plasmodium falciparum (12).

The authors recognized the need for developing nosodes from the SARS-CoV-2 to explore it's prophylactic and therapeutic potentials. Researchers including the authors have been working on the preparation of nosodes from different sources that include clinical samples, inactivated components, and viral culture. Different methods are proposed for nosode preparation, however, till 4th June 2020, there are no documented or approved coronavirus nosodes available for prescription worldwide.

Most of the currently available homeopathic nosodes, such as Tuberculinum (13), Medorrhinum (14), Syphilinum (15), Psorinum (16) and more, were prepared using the clinical samples over 130 years ago.

\section{Objective}

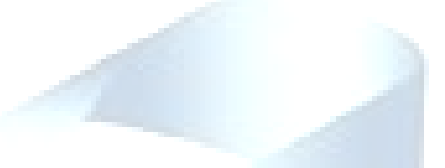

The objective of the study is to scientifically and systematically prepare Coronavirus nosodes from a clinical sample, inactivated strain, and spike glycoprotein of the SARS-CoV-2 virus.

\section{Materials and methods}

All procedures were approved by the Institutional Ethics Committee (Certificate number: HITRT/IBSC/2020/C-11) and Institutional Biosafety Committee of Haffkine Institute (Certificate no. HITRT/IEC/Approval/2020/02).

\section{Information on the source materials used in preparing the nosode}

\section{Clinical sample}

An oropharyngeal swab of a patient collected in Viral Transport Medium (VTM) infected by the SARSCov-2 virus.

\section{Heat inactivated SARS-CoV-2}

Severe Acute Respiratory Syndrome-related Coronavirus (SARS-CoV-2), isolate Novel Coronavirus, 2019-nCoV/USA-WA1/2020 was isolated from an oropharyngeal swab from a patient with a respiratory illness who had recently returned from travel to the affected region of China and developed the clinical disease (COVID-19) in January 2020 in Washington, USA. The complete genome of SARS-CoV-2, USA-WA1/2020 has been sequenced -the isolate - GenBank: MN985325 and after one passage in Vero cells - GenBank: MT020880. 
Inactivation

SARS-CoV-2 isolate has been inactivated by the supplying agency by heating to $65^{\circ} \mathrm{C}$ for 30 minutes.

\section{Quantity used}

Approximately $0.25 \mathrm{~mL}$ (Strength: $3.75 \times 10^{8}$ genome equivalents $/ \mathrm{mL}$ ) of heat-inactivated, clarified cell lysate and supernatant from Vero E6 cells infected with SARS-CoV-2 isolate .

\section{Strength of Inactivated source material used}

Genome Copy Number Using BioRad QX200 Droplet Digital PCR (ddPCR ${ }^{\mathrm{TM}}$ ) System- $3.75 \times 10^{8}$ genome equivalents/mL.

\section{Spike glycoprotein}

A recombinant form of the spike glycoprotein Receptor Binding Domain (RBD) from severe acute respiratory syndrome-related coronavirus 2 (SARS-CoV-2), Wuhan-Hu-1 (GenPept: QHD43416) was produced in Human Embryonic Kidney HEK293 cells and purified by nickel affinity chromatography. It contains 223 residues of the SARS-CoV-2 spike glycoprotein RBD and features a C-terminal hexahistidine tag.

\section{Quantity used}

Protein Concentration by Bradford Assay is $0.25 \mathrm{mg}$ per $\mathrm{mL}$ and the amount of glycoprotein per vial is $25 \mu \mathrm{g}$

\section{Strength of Spike glycoprotein}

Protein Concentration by Bradford Assay is $0.25 \mathrm{mg}$ per $\mathrm{mL}$

\section{Identification}

The presence of the virus in the source sample was ascertained by Real-Time Reverse Transcriptase Polymerase Chain Reaction (qRT-PCR)

\section{A. Preparation}

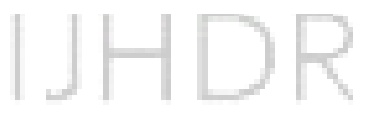

\section{A1. Clinical sample}

\section{Medicine preparation facility}

All standard guidelines for handling SARS-CoV-2 clinical samples were followed, and the nosode was prepared at Haffkine Institute, Mumbai. The samples were handled in a Biosafety Level-2 (BSL2) containment lab with BSL-3 practices. The sample handling person wore two layers of PPE (Personal Protective Equipment), surgical scrub, polypropylene coverall with non-woven fabrics, put on N- 95 mask, double layer of gloves, and safety eye goggles. The room was designed with a dynamic pass box and, in such a way, the inlet-outlet with positive pressure was maintained. Samples were transferred with micropipettes and the pipette were tips discarded in sodium hypochlorite solution. Proper disinfection measures post work by $70 \%$ alcohol spray and ultraviolet lights, and foggers were done. To keep the environment safe, they have a proper disposal plan with specific bags and an autoclave facility. The nosode was processed in this laboratory with a trained operator. 


\section{Procedure}

1. Clinical sample, an oropharyngeal swab of SARS-Cov-2 positive patient having the lower cycle threshold value was selected for nosode preparation. The sample was stored at minus $80^{\circ} \mathrm{C}$ as per the standard COVID-19 clinical sample storage protocol until the nosode preparation step.

2. The SWAB in Viral Transport Medium (VTM) was labeled as Original Stock Nosode (OSN).

$3.1 \mathrm{c}$ to $4 \mathrm{c}$ potencies were prepared by using Water for Injection (WFI) as a vehicle.

4. $0.03 \mathrm{ml}$ of OSN was taken in a suitable glass bottle allowing one-third space for succussion and 2.97 $\mathrm{ml}$ WFI was added to make $3 \mathrm{ml}$ volume.

5. This bottle was given 10 strokes with the help of hand-potentize in a biosafety cabinet to arrive at 1c potency.

6. Likewise, further potencies were made maintaining a 1:99 dilution ratio. Subsequent potencies of nosode, from $5 \mathrm{c}$ to $30 \mathrm{c}$, were made using alcohol $(91 \% \mathrm{~V} / \mathrm{V})$ as medium

7. Ten strokes were applied at each step of potentization, which were counted with a digital counter attached to the electromechanical device, thereby avoiding counting errors.

8. The torque of $501.27 \mathrm{Nm}$ was imparted during each step of 10 strokes to every potency.

\section{A2. Heat-inactivated SARS-CoV-2}

Medicine preparation facility

Nosodes from Inactivated strain and Spike glycoprotein were prepared in the BSL-2 facility at Gujarati University, Ahmedabad. Gujarat University BSL-2 facility is equipped with a BSL Class III cabinet.

1. Genome Copy Number (Using BioRad QX200 Droplet Digital PCR (ddPCR ${ }^{\mathrm{TM}}$ ) System) $3.75 \times 108$ genome equivalents/mL were used for the preparation.

2. One ml of WFI was added to $0.25 \mathrm{~mL}$ (Strength: $3.75 \times 10^{8}$ genome equivalents $/ \mathrm{mL}$ ) of heatinactivated, clarified cell lysate, and it was labeled as Original Stock Nosode (OSN).

$3.1 \mathrm{c}$ to $4 \mathrm{c}$ potencies were prepared by using WFI as a vehicle.

Steps 4 to 8 are the same as those described under the procedure of the preparation of nosode from a Clinical sample.

\section{A3. Spike glycoprotein}

1. Protein Concentration (by Bradford Assay is $0.25 \mathrm{mg}$ per $\mathrm{mL}$ ) containing $25 \mu \mathrm{g}$ of glycoprotein was used for the preparation.

2. One ml of WFI was added to $25 \mu \mathrm{g}$ of glycoprotein, and it was labeled as Original Stock Nosode (OSN).

3. $1 \mathrm{c}$ to $4 \mathrm{c}$ potencies were prepared by using WFI as a vehicle.

Steps 4 to 8 are the same as those described under the procedure of the preparation of nosode from a Clinical sample.

\section{B. Storage}

Preparations below $6 \mathrm{c}$ potency were stored at $5^{\circ} \mathrm{C}$ and not allowed to freeze.

\section{Caution}

All the nosodes were handled with care and by following aseptic conditions during the process of preparation and storage. 


\section{Safety}

a. Sterility test: The test for ruling out any contamination in usable 30c potency was done as per the requirements of the Indian Pharmacopoeia (IP) (17). Standard test cultures, such as aerobic bacterial culture, anaerobic bacterial culture, and fungal culture, were used as positive controls. Standards, nosodes, and inhibition controls were incubated at $24^{\circ} \mathrm{C}$ and $37^{\circ} \mathrm{C}$ for 14 days. The analytical results were reported as compliant for sterility testing as per the IP.

b. Molecular method of the testing source material: Qualitative RT-PCR tests by Patho-detect using My Lab Discovery Solutions COVID-19 diagnostic kits were done for potencies ranging from 1c to 6c.

\section{Results}

Nosodes, from A1. Clinical sample, A2. Heat-inactivated SARS-CoV-2 and A3. Spike glycoprotein, were prepared for future research and clinical exploration.

Polymerase Chain Reaction (PCR) test for the nosodes from 1c to $6 \mathrm{c}$ was performed. Coronavirus copies were detected only up to 2c potency in the nosode prepared from the clinical sample. In potencies $3 \mathrm{c}$ and above, there was no detectable SARS-CoV-2 RNA material. No human RNA was detected as evidenced by the absence of signals for the RNAse P gene.

As per the Indian Pharmacopoeia (IP) standards, sterility testing for nosode in 29c potency was performed and found compliant with the IP standards.

\section{Discussion}

In addition to the homeopathic rationale of the law of similars, clinical data from homeopathic practitioners, and preclinical and clinical experiments offer enough leads to exploring the nosodes sourced from SARS-Cov-2 against the same, particularly when no effective treatment or preventive vaccines are yet available by August 2020 .

As alcohol is known to denature the viral protein material, water for Injection was used as a vehicle up to $4 \mathrm{c}$ potency based on our previous experience (18) of making nosodes. In our experiment, as the RNA material was detected up to $3 c$ potency, we chose to shift the vehicle to alcohol from $5 c$ potency onwards.

Three nosodes variants thus prepared may be explored for their potential role as prophylactic and therapeutic against COVID-19 as well as for other related conditions based on the homeopathic indications of using the nosodes.

The homeopathic process of potentization is a simple, sophisticated, and scientific technology capable of transforming the source material into nano-materia (19) having proven therapeutic efficacy. The entire category of nosodes remains untapped for its potential. The current COVID-19 pandemic offers a great opportunity to unravel the nosodes, probably as an alternative prophylactic modality.

Since homeopathic nosodes are not vaccines and they do not retain harmful biological material in the potentized form, the rules of making the vaccines should not apply to the nosode preparation. The pandemic situations must have a faster regulatory process for the approvals. 
The potentization process of serial dilution $\left(10^{-2}\right)$ at every step from $1 \mathrm{c}$ to $30 \mathrm{c}\left(10^{-60}\right), 200 \mathrm{c}\left(10^{-400}\right)$ leaves non-toxic material in the administrable form, calling for no need for conventional animal toxicity studies as about 1500 homeopathic drugs listed in the various pharmacopeia of India, German, USA, British, and Brazil did not report having undergone animal toxicity studies.

The limitations of this study include a lack of meta-genomic study, viral copy count due to limited resources during the COVID-19 lockdown period. Meta-genomic assay for examining the gene sequencing in the source of the clinical sample will be carried out to rule out any other microbial species as a contaminant.

The preferred usable potencies of nosodes are above 12c, mostly 30c, 200c, and 1000c, which have been found to be free from the infective material of the source organisms. As about $90 \%$ of alcohol is used as a vehicle from $4 \mathrm{c}$ or $5 \mathrm{c}$ and above potencies, it eliminates the possibility of retaining any live viruses or bacteria from the source (20).

All the above points will help the regulators determine policy for making the nosodes distinct from that of developing the vaccine-like drugs.

The process of developing vaccines is quite long due to various challenges. As the process of nosode development is unique and not comparable with that of the vaccines, the nosodes must be made readily explorable during the medically challenging times of pandemics, endemics, and epidemics.

A quick and timely use of nosodes for epidemics and pandemics is best made from clinical samples, inactivated strain, and the spike glycoprotein, now and in the future. The strength of a nosode made by using the clinical samples includes possibly more antigenicity due to the whole virus, quick preparation in the epidemic situation, and cost-effectiveness. The strength of the variant prepared from inactivated strain includes isolated strain and safety.

Another important variant for developing the nosodes includes the use of the viral culture of SARSCov-2 which requires BSL-3 laboratory facility and local regulatory approvals. The development is under process.

With the evolution of microbiology and related technology, the development of the nosodes from the clinical sample may be restricted only to special circumstances where the process of isolation of the organisms (or tissues), quantification, and characterization may have some logistic challenges, as in the case of the COVID-19 pandemic. A clinical sample-based nosode may be urgently required until the time more technically sound, standardized, and higher versions of COVID-19 nosodes are made available. A comparative study in the pre-clinical and clinical setup needs to be carried out to examine the relative efficacy of all the nosode variants.

\section{Conclusion}

Three Coronavirus nosodes sourced from clinical sample, inactivated strain, and spike glycoprotein belonging to SARS-Cov-2 were prepared and standardized by using all acceptable biosafety parameters and examined for sterility and RNA material. Pre-clinical and clinical studies could be done by using these preparations.

\section{Acknowledgment}

We thank Mr. Pawankumar Todkar, Scientific Officer, Haffkine Institute, Institutional Ethics Committee, Institutional Biosafety Committee members of Haffkine Institute for the approval of the project, and Chemo test laboratory, Shivari, Mumbai for performing sterility test for COVID-19

OPEN ACCESS 
nosode from clinical samples. Thanks to the Biosafety Committee and laboratory staff of Gujarat University. Our thanks to Dr. Shivang Swaminarayan and Mr. S B Dangayach for valuable inputs in the process of developing the project. Our sincere thanks to the members of the Scientific Advisory Board of Life Force Foundation Trust for valuable inputs.

\section{CONFLICT OF INTEREST}

One of the authors has patent-pending for nosodes prepared from the corona-related viruses.

\section{References}

(1) WHO Coronavirus Disease (COVID-19) Dashboard. Data last updated: 2020/6/4, 10:41 am CEST. Available at: https://www.who.int/emergencies/diseases/novelcoronavirus-2019

(2) Manchanda RK. Dengue epidemic: What can we offer? Indian J Res Homoeopathy 2015; 9:137-40.

(3) Oberai P, Varanasi R, Padmanabhan M, et al. Effectiveness of Homeopathic Medicines as Add-on to Institutional Management Protocol for Acute Encephalitis Syndrome in Children: An Open-Label Randomized Placebo-Controlled Trial. Homeopathy. 2018;107(3):161-171.

(4) Bracho G. Varela E. Fernández R. et. al Large-scale application of highly diluted bacteria for Leptospirosis epidemic control. Homeopathy 2010; 99: 156e166

(5) Shah R. Clinical trial for the evaluation of a Human Immunodeficiency Virus nosode in the treatment for Human Immunodeficiency Virus-Infected individuals. Indian J Res Homoeopathy. 2015; 9:25-33

(6) Shah R. Clinical trial for the evaluation of a Hep C Nosode in the treatment for Hepatitis C (HCV) positive participants. Homeopathy 2013; 102:207-14

(7) Siqueira CM, et al., Homeopathic medicines for the prevention of influenza and acute respiratory tract infections in children: blind, randomized, placebo-controlled clinical trial, Homeopathy (2015), http://dx.doi.org/10.1016/j.homp.2015.02.006

(8) Gosavia TP. Ghosh P. Kandhare AD. Kumar S. Subhash RR. Bodhankar L. Therapeutic effect of $\mathrm{H}$. pylori nosode, a homeopathic preparation in the healing of chronic $\mathrm{H}$. pylori-infected ulcers in laboratory animals. Asian Pacific Journal of Tropical Disease. 2012;2: S603-611.

(9) Bagai U. Walter NS. Antiplasmodial potential of homeopathic drugs Chelidonium and nosode against Plasmodium berghei infection.J Complement Integr Med. 2014;11(3):195-201

(10)Camerlink I, Ellinger L, Bakker EJ, Lantinga EA. Homeopathy as replacement to antibiotics in the case of Escherichia coli diarrhea in neonatal piglets. Homeopathy. 2010;99(1):57-62

(11)Siqueira CM, Costa B, Amorim AM, Gonçalves M, Féo da Veiga V, Castelo-Branco M, Takyia C, Zancan P, Câmara FP, Couceiro JN, Holandino C. H3N2 homeopathic influenza virus solution modifies cellular and biochemical aspects of MDCK and J774G8 cell lines. Homeopathy. 2013 Jan;102(1):31-40 
(12)Joshi S. Munshi R. Talele G. Shah R. An experimental in vitro study to evaluate the antimalarial activity of select homeopathy preparations. International Journal of Medical and Health Research, 2017;7:65-68

(13)Clarke JH. A Dictionary of Practical Materia Medica, Vol. 3. Available at: http://www.homeoint.org/clarke/t/tub.htm

(14)Boericke W. Pocket manual of homeopathic materia medica. 9th ed. New Delhi: Indian Books and Periodicals Publishers; 2008. p. 424-6

(15)Hering C. Guiding symptoms of our materia medica. Reprint ed, Vol 10. New Delhi: B Jain Publishers; 1989. p. 211

(16)Hering C. The Guiding Symptoms of Our Materia Medica. Reprint. Vol. 8. New Delhi; B. Jain Publishers; 1989. p. 538

(17)Indian Pharmacopoeia. Published by The Indian Pharmacopoeia Commission Ministry of Health and Family Welfare, Government of India. New Delhi. 2010: P. 5758

(18)Shah R. Scientific method of preparing homeopathic nosodes. Indian J Res Homoeopathy 2014; 8:166-74

(19)Chikramane PS, Suresh AK, Bellare JR, Kane SG. Extreme homeopathic dilutions retain starting materials: A nanoparticulate perspective. Homeopathy. 2010; 99:23142

(20)Kampf. Günter. Efficacy of ethanol against viruses in hand disinfection. Journal of Hospital Infection. 2017; 98: 10.1016

Received: Aug 27, 2020. Accepted: Sep 09, 2020.

(C) International Journal of High Dilution Research.

Not for commercial purposes. 